\title{
HVMANITAS
}

\section{Sequendus Aristoteles: da ciência e da natureza na Ratio Studiorum (1599)}

Autor(es): $\quad$ Miranda, Margarida

Publicado por: Faculdade de Letras da Universidade de Coimbra, Instituto de Estudos

URL

persistente:

Clássicos

DOI: $\quad$ DOl:http://dx.doi.org/10.14195/2183-1718_61_10

Accessed : $\quad$ 26-Apr-2023 08:19:48

A navegação consulta e descarregamento dos títulos inseridos nas Bibliotecas Digitais UC Digitalis, UC Pombalina e UC Impactum, pressupõem a aceitação plena e sem reservas dos Termos e Condições de Uso destas Bibliotecas Digitais, disponíveis em https://digitalis.uc.pt/pt-pt/termos.

Conforme exposto nos referidos Termos e Condições de Uso, o descarregamento de títulos de acesso restrito requer uma licença válida de autorização devendo o utilizador aceder ao(s) documento(s) a partir de um endereço de IP da instituição detentora da supramencionada licença.

Ao utilizador é apenas permitido o descarregamento para uso pessoal, pelo que o emprego do(s) título(s) descarregado(s) para outro fim, designadamente comercial, carece de autorização do respetivo autor ou editor da obra.

Na medida em que todas as obras da UC Digitalis se encontram protegidas pelo Código do Direito de Autor e Direitos Conexos e demais legislação aplicável, toda a cópia, parcial ou total, deste documento, nos casos em que é legalmente admitida, deverá conter ou fazer-se acompanhar por este aviso. 
humanitas

\section{Vol. LXI}

IMPRENSA DA UNIVERSIDADE DE COIMBRA

COIMBRA UNIVERSITY PRESS 


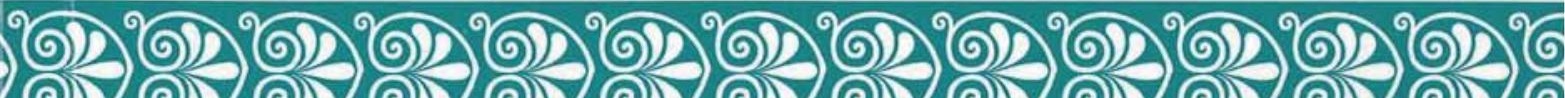

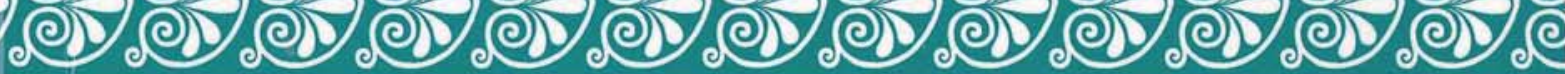

Vol. LXI 


\title{
SEQUENDVS ARISTOTELES. DA CIÊNCIA E DA NATUREZA NA RATIO STVDIORVM (1599)
}

\author{
Margarida Miranda \\ Universidade de Coimbra \\ mmiranda@fl.uc.pt
}

\begin{abstract}
Resumo
A Ratio Studiorum dos Jesuítas foi muito mais do que um curriculum escolar de filosofia e de teologia. Um lugar central é dado aos estudos literários, mas o arquétipo das sete artes liberais continua presente, ao longo de uma linha de continuidade que atravessa a educação no Ocidente, e que torna os termos 'antigo', 'medieval' e 'moderno'relativamente arbitrários. Os estudos previstos pela Ratio são, porém, simultaneamente literários e filosóficos mas também científicos. Através da obra de Aristóteles, as ciências da natureza (física, geografia, meteorologia, biologia, cosmologia, psicologia) constituíam estudo obrigatório, por se entender que predispunham o intelecto para a teologia e estavam ao serviço do seu perfeito conhecimento.

Palavras-chave: Ratio Studiorum; Companhia de Jesus, colégios, ciência, natureza, filosofia, educação, escolástica, Aristóteles.

\footnotetext{
Abstract

The Ratio Studiorum is much more than a high school curriculum on philosophy and theology. Along with the prototype of the seven liberal arts, literary studies are also key in this XVIth century Jesuit document. According to the Ratio, however, the field of studies includes literary, as well as philosophical and scientific knowledge. In fact, insofar as Aristotle's works were a major object of study, natural sciences (e.g. physics, geography, meteorology, biology, cosmology, psychology) were mandatory disciplines. The underlying understanding was that natural sciences' knowledge, besides predisposing the intellect for theological
} studies, was also meant for the perfect knowledge of the Creator.
\end{abstract}


Keywords: Ratio Studiorum, Society of Jesus, high schools, natural sciences, philosophy, education, Scholastic philosophy, Aristotle.

A Ratio Studiorum dos Jesuítas (doravante Ratio) ${ }^{1}$ foi muito mais do que um curriculum escolar de filosofia e de teologia. Um lugar central é dado aos estudos literários, como expressão de uma revalorização activa dos saberes, mas o arquétipo das sete artes liberais continua presente, ao longo de uma linha de continuidade que atravessa a educação no Ocidente, e que torna os termos 'antigo', 'medieval' e 'moderno' relativamente arbitrários.

Os estudos prescritos pela Ratio são simultaneamente literários e filosóficos mas também científicos. Através da obra de Aristóteles, podemos de certo modo afirmar que as ciências da natureza (física, geografia, meteorologia, biologia, cosmologia, psicologia) constituíam estudo obrigatório. Se no plano da valorização da retórica e da educação para a eloquência, a Ratio pertence a uma aetas ciceroniana - para usar a dicotomia de Etienne Gilson (1974: 4) e Marc Fumaroli (1994: 41-43) - no plano da formação filosófica ela pertence genuinamente a uma aetas aristoteliana, esbatendo portanto as fronteiras académicas entre Idade Média e Renascimento.

As Constituições da V Congregação Geral da Companhia (Decreto n. ${ }^{\circ}$ 41) já preconizavam a adopção de Aristóteles, determinando: In Logica et Philosophia naturali et morali et Metaphysica, doctrina Aristotelis sequenda est... Nem se compreenderia que assim não fosse, numa Europa fracturada pelas controvérsias religiosas, em polémica com as doutrinas da Reforma protestante. O Aristóteles prescrito pela Ratio é pois o Aristóteles tomista da chamada Segunda Escolástica, isto é, um Aristóteles baptizado por São Tomás de Aquino, cuja Summa Theologica, por antonomásia e familiaridade, passara a receber o nome de "Partes de São Tomás", e influenciava quer o estudo da filosofia quer o estudo da teologia. ${ }^{2} \mathrm{O}$ Aristóteles tomista é que

${ }^{1}$ Ratio Studiorum da Companhia de Jesus (1599). Regime escolar e curriculum de estudos. Edição bilingue Latim-Português, Introdução, versão e notas por Margarida Miranda. Ratio Studiorum, um modelo pedagógico por José Manuel Martins Lopes S.J., Faculdade de Filosofia de Braga - Universidade Católica Portuguesa, Província Portuguesa da Companhia de Jesus, Edições Alcalá, 2008.

${ }^{2}$ Andrade 1982: 39-60. A Summa Theologica organiza-se efectivamente em três partes, Prima, Secunda e Tertia, que versam respectivamente a Teologia Fundamental, a Teologia Moral e a Teologia Sacramental. A expressão 'Partes de 
trazia, de resto, à teologia cristã, a ideia da justiça e da liberdade humana, e abria o caminho para a doutrina católica da cooperação do livre arbítrio com a graça divina, salvaguardando, portanto, as possibilidades intrínsecas da natureza. Do lado luterano, não esqueçamos, sustentava-se antes a exaltação unilateral da Graça, concebida como substituto de uma natureza humana inteiramente corrompida pelo pecado. ${ }^{3}$

O Aristóteles da Ratio é precisamente o Aristóteles cristianizado em que assentava solidamente o edifício da cultura católica. Mas não deixava de ser o essencial do liceu aristotélico, agora submetido a um exercício de actualização e sistematização que lhe permitiria manter-se de pé no decurso de mais de dois séculos e articular, com uma certa continuidade, a antiguidade e a medievalidade com a modernidade.

Ora, sabemos como a filosofia natural está no coração do pensamento de Aristóteles. Mais de metade do Corpus Aristotelicum ocupa-se de questões de ciência e filosofia da natureza, por vezes em termos propriamente biológicos.

Seria no entanto incorrecto continuar esta reflexão sem esclarecer o conteúdo desta 'ciência' e desta 'filosofia', pois uma e outra consistem no conhecimento das coisas pelas suas causas. De facto, nos livros da Física encontramos abundantes considerações de carácter metafísico e nos livros de Metafísica encontramos abundantes considerações de carácter físico, o que significa que o reconhecimento da autonomia de uma e de outra não se impunha, como aliás era próprio do pensamento antigo. No sentido mais restrito, e para nós mais familiar, a classificação das Ciências é um tema caracteristicamente moderno, aparecendo apenas quando se reconheceu aquilo a que se chamou a independência das ciências particulares com respeito à filosofia. O conhecimento da natureza na Ratio é, pois, um conhecimento a um tempo científico e filosófico.

A fidelidade a Aristóteles era um propósito já formulado pela própria Universidade (como se pode verificar, por exemplo, nos Estatutos da Universidade de Coimbra de 1559) e consagrado na Parte IV das Constituições da Companhia. Adquirira, além disso, força de lei, no regime

São Tomás' teve origem na linguagem académica e tornou-se corrente no tomismo, não obstante o uso de mau gosto, entre os escolares, de expressões como 'andar nas partes de São Tomás', ou 'perder as partes de São Tomás'...

${ }^{3}$ Gilson 1983: 190 ss salienta a importância do tomismo para a restauração da ideia de natureza e da justificação humana, operada pela Contra-Reforma. 
de estudos criado em 1599 para todos os colégios, o qual recomendava aos professores de filosofia que não se afastassem de Aristóteles (Sequendus Aristoteles (...); Ab Aristotele non recedat. [Ratio IX. 2]).

O estatuto primordial de Aristóteles no curriculum académico tornase ainda mais evidente no artigo n. ${ }^{\circ} 12$ do mesmo capítulo da Ratio, onde se sustenta o dever de aristotelicum textum bene interpretari:

O professor esforçar-se-á com diligência por comentar bem o texto de Aristóteles (...). Deve persuadir os seus discípulos de que a sua filosofia será deficiente e como que mutilada se não der grande importância ao estudo daqueles textos.

A fidelidade a Aristóteles, maestro di color che sanno - segundo o epíteto de Dante $($ Inf. 4,131$)$ que espelha o sentir de toda uma época colocava a Ratio na continuidade da mais genuína tradição escolástica. Só os métodos e as fontes utilizados fariam dela tributária das inovações do Humanismo. Podemos acrescentar a redescoberta do texto e das suas fontes, o interesse filológico, o contributo do conhecimento da literatura clássica e da sua pureza linguística para a releitura de Aristóteles e acima de tudo o carácter sistemático e integral do aristotelismo desenvolvido, que não ignorava a escolástica árabe. ${ }^{4}$

Ao contrário do que se possa pensar, o aristotelismo não atraía apenas a Europa da Contra-Reforma. Embora algumas escolas mais próximas da inspiração de Calvino abandonassem Aristóteles em nome de um conhecimento exclusivamente dependente da Sagrada Escritura, Melanchton e Johannes Sturm haviam-no proposto também ao cânone da educação luterana. Deste modo, quer em matéria literária quer em matéria filosófica, podemos afirmar que a Ratio Studiorum se afigura como a resposta católica à missão de educar a Europa. Não nos deve pois espantar que o estudo da

${ }^{4}$ A Ratio recomenda prudência no uso dos textos de Averróis e de Alexandre, sem, no entanto, os proibir (IX. 3-5). Por isso, o Curso conimbricense mostra conhecer abundantemente as teses daqueles comentadores antigos, assumindo um carácter de aristotelismo integral, greco-romano e árabo-medieval. Na verdade, os Commentarii não se limitam a expor uma tese dogmática sobre cada um dos problemas filosóficos. Cada tese é arguida, refutada ou corroborada, num apelo ao exercício da liberdade de pensar, de modo a concluir por aquilo que se chamaria tese oficial. Mesmo as teses consideradas erros eram expostas, embora não ensinadas, isto é, não apresentadas como defensáveis. 
filosofia seja colocado ao serviço do estudo da teologia, segundo a antiga fórmula philosophia 'ancilla theologiae'. De facto, essa é a concepção exposta desde o início aos professores de filosofia (Ratio IX. 1):

Uma vez que as artes liberais ${ }^{5}$, tal como as ciências naturais, predispõem o intelecto para a teologia, estão ao serviço do seu perfeito conhecimento e da sua aplicação prática e contribuem por si só para esse fim, o professor de filosofia deverá tratá-las com toda a diligência, procurando em tudo sinceramente a honra e a glória de Deus, de modo a preparar os seus alunos (...) para a teologia e, acima de tudo, a despertar neles o desejo de conhecerem o seu Criador.

Segundo o magistério jesuítico, esta constituía a regra $n .{ }^{\circ} 1$ dos professores de filosofia. As artes e as ciências naturais predispunham o intelecto para o perfeito conhecimento do Criador, principal objectivo do ensino filosófico e científico. Ou por outras palavras, a teologia era a causa final da filosofia. Por isso o professor de filosofia, além da formação filosófica, já devia possuir estudos completos de teologia: Salvo por grave necessidade, escreve a Ratio (I. 16), (...) os professores de filosofia já deverão ter concluído não apenas o curso de teologia como também o biénio de repetição, para poderem ter conhecimentos mais seguros e mais proveitosos ao serviço da teologia.

Por detrás desta clara hierarquia entre as ciências, encontra-se o pensamento aristotélico da classificação das ciências de acordo com a dignidade ontológica do seu objecto. A Metafísica é a filosofia primeira pois ocupa-se das realidades que se encontram acima das físicas, as realidades transcendentes - considerada a sua supremacia ontológica em relação às realidades empíricas. A filosofia segunda, por sua vez, corresponde à filosofia 'física' ou seja, natural, e é a que tem como objecto a investigação da realidade sensível, intrinsecamente caracterizada pela mudança e o movimento.

A Ratio não podia deixar de espelhar esta ordenação científica. No entanto, as semelhanças epistemológicas ultrapassam o plano formal da estrutura curricular. Como se vê, o que encontramos na Ratio Studiorum é

${ }^{5}$ As artes liberales (ou bonae ou ingenuae) designam as artes intelectuais, na esteira da tradição do triuium e do quadriuium. 
uma concepção 'filosófica' da natureza, mais do que 'científica', no sentido moderno do termo. Ora, esta concepção, que se manterá vigente até à revolução iniciada por Galileu, era a expressão de um edifícioepistemológico com uma aceitação de cerca de vinte séculos.

O curso de filosofia previsto na Ratio baseava-se essencialmente na obra de Aristóteles. No primeiro ano, estudava-se a lógica (a propedêutica geral a todas as outras ciências), pela mão de Francisco Toledo e de Pedro da Fonseca. O primeiro era o cardeal jesuíta de Córdova (1532-1596), conhecido pelos seus comentários a Aristóteles e à Suma Teológica de São Tomás. O segundo, Pedro da Fonseca (1528-1599), era o jesuíta português autor dos Institutionum Dialecticarum Libri Octo (Coimbra, 1574), que fizeram dele um dos principais representantes da segunda escolástica e lhe valeram o título de 'Aristóteles português'. Era professor no Colégio das Artes de Coimbra, quando recebeu a missão de preparar um curso de filosofia que poupasse aos alunos e estudantes o trabalho diário de escrever. Nascido por obra colectiva dos professores de Coimbra (que lhe deram o nome), ali teve, pois, origem o célebre Curso Conimbricense, destinado ao magistério universal da Companhia e conhecedor de ampla difusão, em toda a Europa.

O artigo ${ }^{\circ} 9$ do capítulo IX da Ratio descreve cuidadosamente quais os temas a privilegiar e quais os que se podiam omitir, bem como as noções analíticas mais indispensáveis para a prática frequente das disputas. São referidos nomeadamente os livros Da Interpretação (Peri Hermeneias) e os Primeiros Analíticos, mas também os Tópicos e as Refutações Sofísticas (IX. 9.4 e 6). Parece todavia que, para o magistério jesuítico, a lógica funciona essencialmente como propedêutica da teologia ou suporte racional da sua estrutura sistemática. Sinal disso é o facto de as questões sobre os universais, as categorias, os futura contingentia, as relações entre a ciência e a crença, etc, incluírem evidentes conotações teológicas, como observa Amândio A. Coxito a propósito dos mestres conimbricenses (2001: 519).

A classificação das ciências encerrava o estudo preparatório do primeiro ano, como se pode ler uma pouco mais à frente. Questões como a divisão das ciências, [os graus da] abstracção, o [conhecimento] teórico e prático, a hierarquia dos saberes eram objecto de estudo, bem como o livro segundo da Física sobre os diferentes modos de proceder da física e da matemática, e o livro segundo Da Alma, sobre a definição (IX. 9.5).

A preocupação pela ordem e metodologia, que transparece ao longo de todo o programa literário, filosófico e teológico, transformava-se agora 
no próprio objecto de estudo e era levada à discussão interna, como preparação para o estudo de toda a filosofia natural.

O segundo ano de estudos consistia nos oito livros da Física, os livros Sobre o Céu e o primeiro livro do Tratado da Geração e Corrupção, à excepção de algumas matérias que a Ratio considerava deverem pertencer antes à matemática e à metafísica (por exemplo, o número das inteligências, o carácter infinito do primeiro motor). Estudava-se assim o céu, o mar e a terra como elementos de um conjunto cósmico (com a sua integração numa ordem universal), os corpos sublunares e as razões pelas quais são gerados e se corrompem.

Por fim, no período do Verão, o professor de filosofia dava início às aulas de Meteorologia segundo os livros homónimos de Aristóteles (o trovão, o raio, os cometas, o arco-íris, os ventos e as tempestades, a água e os vários estados aquosos, os mares e as marés, as fontes e os rios, os terramotos e os metais).

No terceiro ano, dava-se o livro segundo do Tratado sobre a Geração e Corrupção, o Tratado sobre a Alma e por fim a Metafísica.

Em todo o percurso aristotélico, a Ratio apresenta, no entanto, noções claras sobre a ordenação das matérias a abordar com maior ou com menor profundidade - consoante o Estagirita havia ou não sido ultrapassado pela fé, ou consoante essas matérias pareciam mais adequadas a outras áreas do saber. $\mathrm{Na}$ Metafísica, recomenda a Ratio, omitam-se as questões sobre Deus e sobre as inteligências, pois essas dependem inteiramente (ou em grande parte) das verdades transmitidas pela fé divina (Ratio IX. 11. 2)

Quanto ao primeiro livro do Tratado da Alma, o professor (...) dará tudo aquilo que se refere aos órgãos dos sentidos, mas não fará digressões sobre anatomia ou outras matérias que são próprias da medicina. ${ }^{6}$

Uma noção de ordem e de método preside a todo o texto da Ratio e leva os seus autores a intervir até na ordem que presidia às obras de Aristóteles, deixando para a medicina aquilo que entendiam ser medicina e para a matemática aquilo que entendiam ser matemática, como a geometria e a aritmética (IX. 10. 1-2 e 11. 1-2). Não são porém, especificadas ciências cujo objecto pertencia em parte à matemática, em parte à filosofia da

${ }^{6}$ Ratio IX. 11. 1. Resta inquirir com que rigor os autores dos Comentários observam a distinção estabelecida pela Ratio entre medicina e filosofia natural. 
natureza, como a música e a astronomia (podendo ainda acrescentar-se a cosmografia, a geografia e a topografia).

Um caso muito claro de preocupação pela ordem e o método é a regra n. ${ }^{\circ} 1$ para o professor de filosofia moral (Ratio: X. 1)

O professor de filosofia moral deve ter em conta que não faz parte das suas atribuições divagar sobre questões teológicas, mas sim explicar douta e gravemente, e seguindo de perto o texto, os principais capítulos da ciência moral contidos nos dez livros da Ética de Aristóteles.

A opção da Ratio sobre o ensino da ética constitui um dos pontos mais inovadores, no que se refere ao esforço por delimitar as ciências. O texto de Aristóteles é chamado ao primeiro plano, substituindo assim as doutrinas tradicionais dos estóicos. Além disso, ao contrário do ensino universitário, a ética deixa de ser ensinada juntamente com a teologia para receber autonomia e constituir-se como um curso próprio - a filosofia moral. ${ }^{7}$

Mas voltemos à Física de Aristóteles. A Física aristotélica não se limitava a investigar a natureza em geral, mas também os seres que estão no universo: inanimados e animados, animados que carecem de razão, mas também animados providos de razão, isto é, o Homem. A distinção entre alma vegetativa, sensitiva e intelectiva resulta assim num tratado sobre o nascimento, nutrição e crescimento do ser vivo, sobre a sensação e o movimento dos animais, sobre o conhecimento, deliberação e eleição do ser humano. Os oito livros da Física tratavam conceitos fundamentais da filosofia da natureza, como o próprio conceito de 'natureza', o movimento e a sua origem, o espaço, o tempo e o infinito. Mas a verdade é que a filosofia natural alargava-se também aos fenómenos do psiquismo humano.

${ }^{7}$ Segundo A. Coxito (2001: 538), o estudo da ética antes da teologia justifica-se pela necessidade de ministrar, nesse domínio, uma formação básica aos estudantes que não se destinassem ao sacerdócio. Observe-se, curiosamente, que, apesar das referências claras da Ratio ao texto de Aristóteles, no Curso Conimbricense, no tratado que M. de Góis redigiu para comentar a Ética, o texto de Aristóteles encontra-se praticamente ausente. Embora seja de 1592, posterior portanto à primeira versão da Ratio, o tratado só remotamente pode considerarse um comentário a Aristóteles, pois ele inspira-se mais na Suma de São Tomás. No entanto, a evidente independência que, neste aspecto, os conimbricenses conservam em relação às prescrições da Ratio é comum a outros aspectos do ensino nos colégios, e não deve surpreender-nos demasiado. 
O De Anima estuda a alma e as faculdades comuns aos seres animados; e os chamados Parua Naturalia, que a Ratio não refere mas que o Curso Conimbricense inclui igualmente, analisam temas como a memória e a reminiscência, o sono e a vigília, os sonhos, a respiração, a juventude e a velhice, a vida e a morte, a longevidade e a brevidade da vida.

Os Commentarii produzidos pelo Colégio de Coimbra mostram-se efectivamente apegados à tradição, no que toca à filosofia natural, ao mesmo tempo que abrangem um campo de investigação que se estende muito além do da física moderna, incidindo sobre fenómenos materiais mas também sobre fenómenos psíquicos. Se a Ratio se esforçava constantemente por ordenar didacticamente estas matérias, não podemos deixar de reconhecer que, efectivamente, o domínio da filosofia natural se encontra profundamente interligado com o da metafísica, não sendo de facto possível delimitá-los. Por isso, embora cada uma das obras de Aristóteles incida sobre diferentes matérias, as quaestiones tratadas pelos professores do Curso conimbricense revelam efectivamente que a investigação daqueles fenómenos, integrando todas as ciências da natureza, era feita numa perspectiva rigorosamente filosófica. Se para nós, modernos, a física é a ciência da natureza considerada quantitativamente (no sentido de Galileu), no magistério da Ratio e de Aristóteles a física não ocupa a posição de uma ciência quantitativa mas qualitativa. Mais do que uma 'ciência da natureza', ela corresponde a uma 'ontologia do mundo sensível' ou seja, uma filosofia da natureza genuinamente aristotélica, sem romper os laços com a teologia, antes ao serviço desta última - o que lhe acrescenta uma característica que diríamos genuinamente escolástica. "O universo não é uma realidade experimental, mas um sistema de valores; o sentido do real é dado a priori, por uma finalidade transcendente." (Coxito 2001: 536).

De facto, o que inspira o magistério jesuítico não é apenas o puro revivalismo de Aristóteles, mas a reforma católica da educação da Europa. A redescoberta integral de Aristóteles não podia perder de vista um Aristóteles iluminado pela Revelação e pela noção de criação, aliado portanto à tradição cristã e especialmente à filosofia de São Tomás.

É justo recordar, no entanto, que esta visão essencialmente filosófica da natureza não rejeitava a novidade das ciências experimentais. É sabido como Manuel de Góis, um dos principais autores dos comentários conimbricenses, ao comentar os Libri Physicorum (1592) abandonou algumas ideias feitas sobre o mundo terrestre e soube incorporar conhecimentos já resultantes da experiência cosmonáutica portuguesa. Outros testemunhos 
semelhantes são apresentados por Marcus Hellyer, no âmbito do magistério jesuítico germânico ${ }^{8}$, e por Henrique Leitão e Luís Miguel Carolin (2006), no âmbito do ensino em Portugal - onde se deverá salientar a importância alcançada pela chamada 'Aula da Esfera' no colégio de Santo Antão, com o seu célebre observatório, que o terramoto de Lisboa de 1755 veio a destruir. Em Lisboa efectivamente, o ensino regular da matemática atingiu um nível superior, com particular incidência sobre questões náuticas, elementos de cosmografia e de astronomia para a navegação, o uso de instrumentos náuticos e a construção de cartas náuticas, globos, etc. (Albuquerque 1974 e Leitão 2008)

Contudo, todos esses fenómenos particulares só ganhavam sentido num contexto metafísico e teológico mais global. No horizonte intelectual da Ratio que presidia à educação dos Jesuítas havia certamente lugar para as novas descobertas científicas, mas era impossível confinar o saber dentro daqueles estreitos limites. Antes de mais, o mundo é 'criatura' e a natureza é manifestação de Deus. O mundo não é visto como uma realidade experimental, antes como um sistema de valores, cujo sentido não está nele mas numa finalidade 'transcendente'. Portanto, de acordo com a teoria cosmológica da perfeição e da harmonia do universo, o fim principal da ciência era justamente mostrar os desígnios de Deus.

Se com a secularização da consciência, o Renascimento pôs em causa esta forma mentis milenar e converteu os fins 'transcendentes' em objectivos 'imanentes', não podemos deixar de ter presente que não era de facto esse o universo intelectual da Ratio, nem da chamada Segunda Escolástica, nem do Curso Conimbricense. Pelo contrário, como começámos por ler na Ratio, as ciências naturais, [predispunham] o intelecto para a teologia e estavam ao serviço do seu perfeito conhecimento.

Eis provavelmente a maior distância que nos separa dessa harmonia ideal com a Natureza, que não era certamente uma Natureza esgotada, que parece revoltar-se contra o Homem. Depois da secularização da revolução científica, a mundividência da Ratio convida-nos a reconciliar a ciência com os valores, talvez a recuperar o mesmo olhar sobre a criação: um olhar aberto ao sagrado.

${ }^{8} \mathrm{O}$ autor afirma que entre 1600 e 1773 o curriculum jesuítico acabou por sofrer uma transformação radical. Na década de 1760, já havia quem expusesse a doutrina de Copérnico, enquanto outras escolas continuavam a sustentar que o heliocentrismo era apenas uma hipótese. 
Sequendus Aristoteles. Da Ciência e da Natureza na Ratio Studiorum (1599) 189

\section{Bibliografia}

Albuquerque, Luís de (1974), “A aula da Esfera do Colégio de Santo Antão no séc. XVII" in Estudos de História. Coimbra: Universidade de Coimbra, vol. 2: 127-200.

Andrade, A. A. Banha de (1982), "S. Tomás de Aquino no Período Áureo da Filosofia Portuguesa" in Contributos para a História da Mentalidade Pedagógica, Lisboa: Imprensa Nacional Casa da Moeda, 39-60.

CARolin, Luís Miguel e Leitão, Henrique (2006), "Natural philosophy and Mathematics in Portuguese Universities, 1550-1650" in M. Feingold and V. Navarro-Brotóns (eds.), Universities and Science in the Early Modern Period, Dordrecht: Springer, 153-168.

Conimbricenses, Commentarii Colegii Conimbricensis. http:// saavedrafajardo.um.es/BIBLIOTECA/IndicesW.nsf/FConimbricense sW2?Openform\&Orden=1\&imag=2\#IR3. Acedido em 29.04.09.

Coxito, Amândio (2001), "O Curso Conimbricense" in Calafate, Pedro (Dir.), História do Pensamento filosófico português. Vol. II Renascimento e Contra-Reforma, Lisboa: Caminho, 503-543.

Fumaroli, M. (1994), L'âge de l'éloquence, Paris: Albin Michel.

GILson, Etienne (1974), «Le Message de l'Humanisme», in F. Simone (ed.)

Culture et Politique en France à l'époque de l'Humanisme et de la Renaissance, Torino: Accademia delle Scienze, 3-9.

Gilson, Etienne (1974), Les Idées et les Lettres. Paris: J. Vrin.

GILson, Etienne (1983), Humanisme et Renaissance. Paris: J. Vrin.

Gilson, Etienne (1983), Le Thomisme. Introduction a la Philosophie de Saint Thomas d'Aquin. Sixième édition revue, Paris: Vrin.

Gomes, Pinharanda (2005), Os Conimbricenses, Lisboa: Guimarães Ed. Hellyer, Marcus (2005), Catholic Physics. Jesuit Natural Philosophy in Early Modern Germany, Indiana: Notre Dame University Press.

LeItão, Henrique e Martins, Lígia (2008), Sphæra Mundi: A Ciência na Aula da Esfera. Manuscritos científicos do Colégio de Santo Antão nas colecções da BNP, Lisboa: Biblioteca Nacional de Portugal.

Martins, António Manuel, "The Conimbricenses. Introductory note to the Commentarii Collegii Conimbricensis Societatis Iesu" http://saavedrafajardo.um.es/WEB/archivos/Conimbricenses_ Presentacion.pdf. (Acedido em 29.04.09).

Ratio Studiorum da Companhia de Jesus (1599). Regime escolar e curriculum de estudos. Edição bilingue Latim-Português, Introdução, 
versão e notas por Margarida Miranda. Ratio Studiorum, um modelo pedagógico por José Manuel Martins Lopes S.J., Faculdade de Filosofia de Braga - Universidade Católica Portuguesa, Edições Alcalá, 2008.

Schmitт, Charles B., (1983), Aristotle and the Renaissance, Harvard University Press. 